\title{
GAMBARAN PARTISIPASI MASYARAKAT DALAM PROGRAM PENGENDALIAN VEKTOR DBD DI WILAYAH KERJA PUSKESMAS AIR DINGIN
}

\author{
Overview of Community Participation in DBD Vector Control Programs \\ in Working Areas Air Dingin Health Center
}

\author{
Novia Wirna Putri ${ }^{1}$, Sevilla Ukhtil Huvaid ${ }^{2}$ \\ ${ }^{1,2}$ Dosen Fakultas Kesehatan Masyarakat Universitas Baiturrahmah Padang \\ Email: noviawirnaputri@fkm.unbrah.ac.id
}

\begin{abstract}
Abstrak
Demam Berdarah Dengue (DBD) menjadi salah satu masalah kesehatan masyarakat penting di Indonesia. Kasus demam berdarah pada tahun 2015 di Kota Padang mengalami peningkatan yang cukup signifikan yaitu sebesar 1.126 kasus (IR = 124,8 per 100.000 penduduk) dengan jumlah kematian 8 orang $(\mathrm{CFR}=$ 0,7\%). Puskesmas Air Dingin merupakan salah satu puskesmas yang ada di Kota Padang dengan wilayah kerja yang mengalami peningkatan kasus DBD cukup signifikan di tahun 2015 dengan IR sebesar 361,5 per 100.000 penduduk. Tujuan penelitian adalah untuk menganalisis partisipasi masyarakat dalam program pengendalian vektor DBD di wilayah kerja Puskesmas Air Dingin Kota Padang tahun 2018. Jenis penelitian ini adalah penelitian deskriptif. Sampel berjumlah 99 orang yang diambil dengan teknik proportional random sampling. Analisis data meliputi analisis univariat partisipasi masyarakat dalam pengendalian vektor yaitu modifikasi lingkungan, manipulasi lingkungan, pengendalian fisik, pengendalian kimia, pengendalian biologi dan keberadaan jentik. Hasil penelitian menunjukkan bahwa sebesar 52,5\% rumah responden positif jentik, sebesar 32,3\% responden tergolong dalam kategori buruk melakukan modifikasi lingkungan, sebesar 58,6 \% responden tergolong dalam kategori buruk melakukan manipulasi lingkungan, sebesar 30,3 \% responden tergolong dalam kategori buruk melakukan pengendalian fisik, sebesar $78,8 \%$ responden tergolong dalam kategori buruk melakukan pengendalian kimiawi, dan sebesar 35,4\% responden tergolong dalam kategori buruk melakukan pengendalian biologi dalam program pengendalian vektor DBD di wilayah kerja Puskesmas Air Dingin. Disarankan kepada pihak Puskesmas Air Dingin untuk dapat mensosialisasikan kepada masyarakat mengenai program pengendalian vektor DBD baik dalam aspek modifikasi lingkungan, manipulasi lingkungan, pengendalian fisik, kimia dan biologi.
\end{abstract}

Keyword : DBD, vektor, lingkungan

\begin{abstract}
Dengue Hemorrhagic Fever (DHF) is one of the important public health problems in Indonesia. Cases of dengue fever in the city of Padang in 2015 experienced a significant increase in the amount of 1,126 cases (IR $=124.8$ per 100,000 population) with a total death of 8 people $(\mathrm{CFR}=0.7 \%)$. The Cold Water Health Center is one of the health centers in the city of Padang with a work area that has a significant increase in dengue cases in 2015 with an IR of 361.5 per 100,000 population. The research objective was to analyze community participation in the DHF vector control program in the working area of the Cold Water Health Center in Padang City in 2018. This type of research was descriptive research. The sample is 99 people taken by proportional random sampling technique. Data analysis includes univariate analysis of community participation in vector control, namely environmental modification, environmental manipulation, physical control, chemical control, biological control and the existence of larvae. The results showed that $52.5 \%$ of respondents were larvae positive, $32.3 \%$ of respondents belonged to the bad category of environmental modification, $58.6 \%$ of respondents belong to the bad category of environmental manipulation, amounting to $30.3 \%$ of respondents classified in the bad category is physical control, $78.8 \%$ of respondents belong to the bad category of chemical control, and $35.4 \%$ of respondents belong to the bad category of biological control in the DHF vector control program in the working area of the Cold Water Health Center. It is recommended to the Air Dingin Health Center to be able to socialize to the public regarding DHF vector control programs both in aspects of environmental modification, environmental manipulation, physical, chemical and biological control.
\end{abstract}

Keyword: DBD, vector, environment 


\section{PENDAHULUAN}

Demam Berdarah Dengue (DBD) adalah penyakit yang disebabkan oleh empat serotipe virus dengue yang ditularkan melalui gigitan nyamuk terinfeksi khususnya nyamuk Aedes aegypti dan Aedes albopictus yang terdapat hampir di seluruh pelosok Indonesia. Pada tahun 2015, di Indonesia jumlah penderita DBD yang dilaporkan sebanyak 129.650 kasus dengan jumlah kematian sebanyak 1.071 kasus (Incidence Rate $(\mathrm{IR})=50,75$ per 100.000 penduduk dan Case Fatality Rate $=0,83 \%$ ). Angka kejadian DBD pada tahun 2015 di Indonesia jika dibandingkan tahun 2014 dengan kasus sebanyak 100.347 kasus serta IR 39,80 per 100.000 penduduk mengalami peningkatan (Kementerian Kesehatan RI, 2016).

Kota Padang merupakan salah satu daerah endemis DBD di Provinsi Sumatera Barat dan tidak ada satu kecamatanpun yang bebas dari DBD. Pada tahun 2015 mengalami peningkatan kasus yang cukup signifikan yaitu dengan jumlah kasus 1.126 kasus $(I R=124,8$ per 100.000 penduduk) dengan jumlah kematian 8 orang $(\mathrm{CFR}=$ 0,7\%) (Dinkes Provinsi Sumbar, 2016).

Puskesmas Air Dingin merupakan salah satu puskesmas di Kota Padang dengan wilayah kerja yang mengalami peningkatan kasus Demam Berdarah cukup signifikan pada tahun 2015. Pada tahun 2013 IR DBD Puskesmas Air Dingin sebesar 177,95 per 100.000 penduduk, kemudian turun di tahun $2014 \mathrm{IR}=80,8$ per 100.000 penduduk, dan di tahun 2015 mengalami peningkatan yaitu sebesar $I R=361,5$ per 100.000 penduduk. Wilayah kerja Puskesmas Air Dingin meliputi tiga kelurahan yaitu Kelurahan Balai Gadang, Aia Pacah, dan Lubuk Minturun Sungai Lareh (Dinkes Kota Padang, 2016).

Untuk memutus mata rantai penularan penyakit DBD, pemerintah bersama masyarakat harus melakukan upaya pencegahan dan pengendalian DBD. Upaya tersebut dilakukan dengan program pengendalian vektor secara intensif untuk memberantas nyamuk Aedes spp dalam upaya memperkecil wilayah endemis DBD dan sasarannya yaitu kecamatan endemis DBD.
Pelaksanaan program pengendalian DBD tanpa adanya keterlibatan masyarakat tidak akan mencapai keberhasilan. Partisipasi aktif masyarakat secara berkesinambungan sangat dibutuhkan agar program pemberantasan penyakit DBD dapat terlaksana dengan luaran tercapainya penurunan kasus DBD. Partisipasi masyarakat dapat dilihat dari kegiatan pengendalian vektor seperti modifikasi lingkungan, manipulasi lingkungan, pengendalian fisik, pengendalian kimia, dan pengendalian biologi (Prasetyowati, 2015).

\section{METODE PENELITIAN}

Jenis penelitian ini adalah penelitian deskriptif. Sampel berjumlah 99 orang yang diambil dengan teknik proportional random sampling. Analisis data meliputi analisis univariat partisipasi masyarakat dalam pengendalian vektor yaitu modifikasi lingkungan, manipulasi lingkungan, pengendalian fisik, pengendalian kimia, dan pengendalian biologi dan keberadaan jentik di wilayah kerja Puskesmas Air Dingin. Penelitian dilakukan pada tahun 2018 di wilayah kerja Puskesmas Air Dingin yang meliputi tiga kelurahan yaitu Kelurahan Balai Gadang, Air Pacah, dan Lubuk Minturun Sungai Lareh.

\section{HASIL DAN PEMBAHASAN}

Puskesmas Air Dingin merupakan salah satu puskesmas yang ada di Kota Padang. Luas wilayah kerja adalah $\pm 183,96 \mathrm{~km}^{2}$ yang terdiri dari tiga kelurahan yaitu Kelurahan Balai Gadang, Kelurahan Lubuk Minturun, dan Kelurahan Aia Pacah.

Jumlah penduduk di wilayah kerja Puskesmas Air Dingin tercatat sebanyak $8836 \mathrm{KK}$ yang terdiri dari Kelurahan Balai Gadang 4.006 KK, Kelurahan Air Pacah $2.586 \mathrm{KK}$, dan Kelurahan Lubuk Minturun $2.244 \mathrm{KK}$.

\section{Modifikasi Lingkungan}

Distribusi responden berdasarkan kategori modifikasi lingkungan dibagi menjadi dua yaitu kategori buruk dan baik. Gambaran distribusi frekuensi variabel modifikasi lingkungan dalam program pengendalian vektor DBD dapat dilihat pada tabel 5.1 dibawah ini. 
Tabel 5.1 Distribusi Frekuensi Responden berdasarkan Kategori Modifikasi Lingkungan

\begin{tabular}{ccc}
\hline $\begin{array}{c}\text { Modifikasi } \\
\text { Lingkungan }\end{array}$ & f & $\mathbf{\%}$ \\
\hline Buruk & 32 & 32,3 \\
Baik & 67 & 67,7 \\
Total & $\mathbf{9 9}$ & $\mathbf{1 0 0}$ \\
\hline
\end{tabular}

Hasil penelitian menunjukkan bahwa dari 99 responden, terdapat 32,3\% responden yang tergolong dalam kategori buruk dalam melakukan modifikasi lingkungan.

Menurut Kusnoputranto (2000), modifikasi lingkungan adalah suatu transformasi fisik permanen (jangka panjang) terhadap tanah, air, dan tumbuh - tumbuhan untuk mencegah/ menurunkan habitat jentik tanpa mengakibatkan kerugian bagi manusia. Kegiatan-kegiatan yang dapat dilakukan untuk modifikasi lingkungan antara lain perbaikan pipa aliran air, menyediakan talang air, merubah rawa - rawa menjadi sawah atau kolam ikan, dan lain sebagainya.

Berikut dapat dilihat tabel distribusi frekuensi hasil jawaban kuesioner untuk variabel modifikasi lingkungan.

Tabel 5.2 Distribusi Frekuensi Hasil Jawaban Kuesioner berdasarkan Kategori Modifikasi Lingkungan

\begin{tabular}{clcc}
\hline No & \multicolumn{1}{c}{$\begin{array}{c}\text { Pernyataan } \\
\text { Kuesioner }\end{array}$} & $\begin{array}{c}\text { Ya } \\
(\mathbf{\%})\end{array}$ & $\begin{array}{c}\text { Tidak } \\
(\mathbf{\%})\end{array}$ \\
\hline 1 & $\begin{array}{l}\text { Memperbaiki pipa } \\
\text { aliran air yang rusak }\end{array}$ & 93,9 & 6,1 \\
\hline 2 & Mempunyai talang air & 13,1 & 86,9 \\
\hline 3 & $\begin{array}{l}\text { Memperbaiki talang air } \\
\text { jika rusak }\end{array}$ & 10,1 & 89,9 \\
\hline 4 & $\begin{array}{l}\text { Jika ada rawa-rawa di } \\
\text { lingkungan, } \\
\text { merubahnya menjadi } \\
\text { sawah, kolam ikan, } \\
\text { atau pemukiman } \\
\text { lainnya }\end{array}$ & 18,2 & 81,8 \\
\hline 5 & $\begin{array}{l}\text { Melakukan perbaikan } \\
\text { got/ parit yang rusak } \\
\text { untuk mengalirkan } \\
\text { genangan air }\end{array}$ & 61,6 & 38,4 \\
\hline 6 & $\begin{array}{l}\text { Mendapatkan } \\
\text { informasi tentang } \\
\text { pengendalian DBD } \\
\text { secara modifikasi } \\
\text { lingkungan dari dinas } \\
\text { kesehatan/ puskesmas }\end{array}$ & & \\
\hline
\end{tabular}

Berdasarkan hasil distribusi frekuensi jawaban responden pada variabel modifikasi lingkungan, diketahui bahwa lebih dari separuh yaitu $81,8 \%$ responden menyatakan bahwa mereka belum melakukan upaya penutupan atau pemanfaatan rawa-rawa yang ada di lingkungannya. Hampir setengah yaitu $38,4 \%$ responden menyatakan bahwa mereka tidak melakukan perbaikan got/ parit yang rusak untuk mengalirkan air yang tergenang, dan 25,3\% responden menyatakan bahwa mereka tidak pernah mendapatkan informasi tentang pengendalian DBD melalui cara modifikasi lingkungan baik dari dinas kesehatan maupun puskesmas setempat.

Hal ini menunjukkan bahwa aspek modifikasi lingkungan dalam program pengendalian vektor DBD belum berjalan sepenuhnya. Masih ada responden yang menyatakan bahwa mereka belum mendapatkan penjelasan tentang program pengendalian vektor DBD baik secara lisan maupun tulisan dari petugas kesehatan. Menurut analisa peneliti, promosi kesehatan pada dasarnya sudah dilakukan oleh pihak puskesmas, hanya saja kurangnya frekuensi penyuluhan, belum lengkapnya materi penyuluhan, dan tidak tepatnya waktu kunjungan menyebabkan masih adanya sasaran masyarakat yang belum mendapatkan pemaparan dan penjelasan terkait program penaggulangan DBD, khususnya dalam hal pengendalian vektor DBD. Selain itu, media promosi kesehatan dalam bentuk tulisan, juga belum terdistribusi dengan baik. Oleh sebab itu, perlu adanya peningkatan peran kader jumantik dalam mengimplementasikan program penanggulangan DBD di masyarakat. Dukungan dan perhatian dari pemerintah setempat juga sangat dibutuhkan dalam mengimplementasikan program penanggulangan DBD.

\section{Manipulasi Lingkungan}

Variabel manipulasi lingkungan dikelompokkan menjadi dua kategori yaitu buruk dan baik. Gambaran distribusi frekuensi variabel manipulasi lingkungan dalam program pengendalian vektor DBD dapat dilihat pada tabel 5.3 di bawah ini. 


\begin{tabular}{|c|c|c|}
\hline \multicolumn{2}{|c|}{ 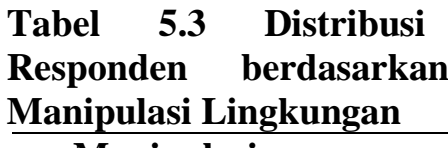 } & $\begin{array}{r}\text { Frekuensi } \\
\text { Kategori }\end{array}$ \\
\hline $\begin{array}{c}\text { Manipulasi } \\
\text { Lingkungan }\end{array}$ & $\mathbf{f}$ & $\%$ \\
\hline Buruk & 58 & 58,6 \\
\hline Baik & 41 & 41,4 \\
\hline Total & 99 & 100 \\
\hline
\end{tabular}

Hasil penelitian menunjukkan bahwa dari 99 responden, terdapat 58,6\% responden yang tergolong dalam kategori buruk dalam melakukan manipulasi lingkungan.

Menurut Kusnoputranto (2000), manipulasi lingkungan adalah suatu pengkondisian sementara yang tidak menguntungkan atau tidak cocok sebagai tempat berkembang biak vektor penular penyakit pada habitatnya. Manipulasi lingkungan terdiri atas kegiatan berulang yang terencana. Beberapa usaha yang memungkinkan dapat dilakukan antara lain membersihkan bak mandi seminggu sekali, memanfaatkan barang bekas, mengganti air pada wadah yang bisa menampung air, dan lain sebagainya.

Berikut dapat dilihat tabel distribusi frekuensi hasil jawaban kuesioner untuk variabel manipulasi lingkungan.

Tabel 5.4 Distribusi Frekuensi Hasil Jawaban Kuesioner berdasarkan Kategori Manipulasi Lingkungan

\begin{tabular}{|c|c|c|c|}
\hline No & $\begin{array}{c}\text { Pernyataan } \\
\text { Kuesioner }\end{array}$ & $\begin{array}{l}\text { Ya } \\
(\%)\end{array}$ & $\begin{array}{c}\text { Tidak } \\
(\%)\end{array}$ \\
\hline 1 & $\begin{array}{l}\text { Membersihkan dan } \\
\text { menyikat dinding } \\
\text { wadah } \\
\text { penampungan air } \\
\text { sekurang- } \\
\text { kurangnya } \\
\text { seminggu sekali }\end{array}$ & 91,9 & 8,1 \\
\hline 2 & $\begin{array}{l}\text { Membersihkan } \\
\text { tumpahan air dari } \\
\text { wadah } \\
\text { penampungan air } \\
\text { sehingga tidak } \\
\text { terjadi genangan air }\end{array}$ & 98 & 2 \\
\hline 3 & $\begin{array}{l}\text { Membersihkan } \\
\text { langsung tumpahan } \\
\text { air dari pipa }\end{array}$ & 91,9 & 8,1 \\
\hline
\end{tabular}

\begin{tabular}{|c|c|c|c|}
\hline & $\begin{array}{l}\text { distribusi sehingga } \\
\text { tidak terjadi } \\
\text { genangan air }\end{array}$ & & \\
\hline 4 & $\begin{array}{l}\text { Melakukan } \\
\text { pemeriksaan } \\
\text { terhadap bangunan } \\
\text { secara berkala } \\
\text { untuk mengetahui } \\
\text { lokasi genangan air }\end{array}$ & 7,1 & 92,9 \\
\hline 5 & $\begin{array}{l}\text { Menggunakan } \\
\text { barang bekas untuk } \\
\text { hal yang } \\
\text { bermanfaat }\end{array}$ & 58,6 & 41,4 \\
\hline 6 & $\begin{array}{l}\text { Menguras bak } \\
\text { mandi minimal } \\
\text { seminggu sekali }\end{array}$ & 87,9 & 12,1 \\
\hline 7 & $\begin{array}{l}\text { Mengganti air pada } \\
\text { wadah yang bisa } \\
\text { menampung air } \\
\text { seminggu sekali }\end{array}$ & 76,8 & 23,2 \\
\hline 8 & $\begin{array}{l}\text { Mengubur barang } \\
\text { bekas yang tak } \\
\text { terpakai }\end{array}$ & 10,1 & 89,9 \\
\hline 9 & $\begin{array}{l}\text { Memangkas } \\
\text { rumput dan semak } \\
\text { yang tinggi di } \\
\text { halaman }\end{array}$ & 87,9 & 12,1 \\
\hline 10 & $\begin{array}{l}\text { Mendapatkan } \\
\text { informasi tentang } \\
\text { pengendalian DBD } \\
\text { secara manipulasi } \\
\text { lingkungan dari } \\
\text { dinas kesehatan/ } \\
\text { puskesmas }\end{array}$ & 70,7 & 29,3 \\
\hline
\end{tabular}

Berdasarkan hasil distribusi frekuensi jawaban responden pada variabel manipulasi lingkungan, diketahui bahwa hampir seluruh yaitu 92,9 \% responden menyatakan bahwa mereka tidak melakukan pemeriksaan terhadap bangunan tempat tinggal mereka secara berkala untuk mengetahui lokasi genangan air. Hampir seluruh yaitu $89,9 \%$ responden tidak mengubur barang bekas yang tak terpakai, dan $41,4 \%$ responden tidak memanfaatkan barang bekas yang masih bisa terpakai untuk hal - hal yang berguna.

Hal ini menunjukkan bahwa aspek manipulasi lingkungan dalam program pengendalian vektor DBD juga belum berjalan dengan baik. Masih ada 12,1\% 
responden yang menyatakan bahwa mereka tidak menguras bak mandi seminggu sekali, dan $29,3 \%$ responden menyatakan bahwa mereka tidak pernah mendapatkan informasi tentang pengendalian DBD melalui cara manipulasi lingkungan baik dari dinas kesehatan maupun puskesmas setempat.

$$
\text { Menurut analisa peneliti, }
$$

ketidaktahuan masyarakat tentang upaya upaya pengendalian vektor DBD secara spesifik membuat mereka masih ada yang tergolong dalam kategori tidak melakukan upaya manipulasi lingkungan. Promosi kesehatan yang dipaparkan secara umum oleh pihak puskesmas, membuat masyarakat tidak paham benar dan kurang menyadari pentingnya penerapan manipulasi lingkungan dalam upaya pengendalian vektor DBD. Oleh sebab itu perlu dilakukan peninjauan kembali terhadap substansi promosi kesehatan yang akan diberikan oleh tenaga kesehatan kepada masyarakat. Selain itu, kunjungan ke rumah - rumah masyarakat melalui sistem door to door untuk peningkatan pengetahuan dan pengawasan oleh kader jumantik dan pihak puskesmas juga harus lebih digiatkan, agar masyarakat lebih memahami dan merasa diawasi didalam melakukan upaya pengendalian vektor DBD demi keberhasilan program penanggulangan DBD.

\section{Pengendalian Fisik}

Distribusi responden berdasarkan kategori pengendalian fisik dibagi menjadi dua yaitu kategori buruk dan baik. Gambaran distribusi frekuensi variabel pengendalian fisik dalam program pengendalian vektor DBD dapat dilihat pada tabel 5.5.

Tabel 5.5 Distribusi Frekuensi Responden berdasarkan Kategori Pengendalian Fisik

\begin{tabular}{ccc}
\hline Pengendalian Fisik & f & \% \\
\hline Buruk & 30 & 30,3 \\
Baik & 69 & 69,7 \\
Total & 99 & 100 \\
\hline
\end{tabular}

Hasil penelitian menunjukkan bahwa dari 99 responden, terdapat 30,3\% responden yang tergolong dalam kategori buruk dalam melakukan pengendalian fisik.

Pengendalian secara fisik adalah pengendalian untuk mengurangi atau menghindari gigitan nyamuk atau gangguan nyamuk dilakukan dengan pemasangan kawat kasa (kawat nyamuk) pada semua lubang yang ada di rumah, seperi lubang angin, jendela, pintu dan lainnya. Cara ini sangat baik dan bersifat permanen, walaupun dalam pembuatannya diperlukan biaya yang mahal. Selain itu, tidur dengan menggunakan kelambu juga sangat dianjurkan untuk mengurangi gigitan nyamuk waktu tidur di daerah endemis (Jingga, 2011).

Berikut dapat dilihat tabel 5.6 distribusi frekuensi hasil jawaban kuesioner untuk variabel pengendalian fisik.

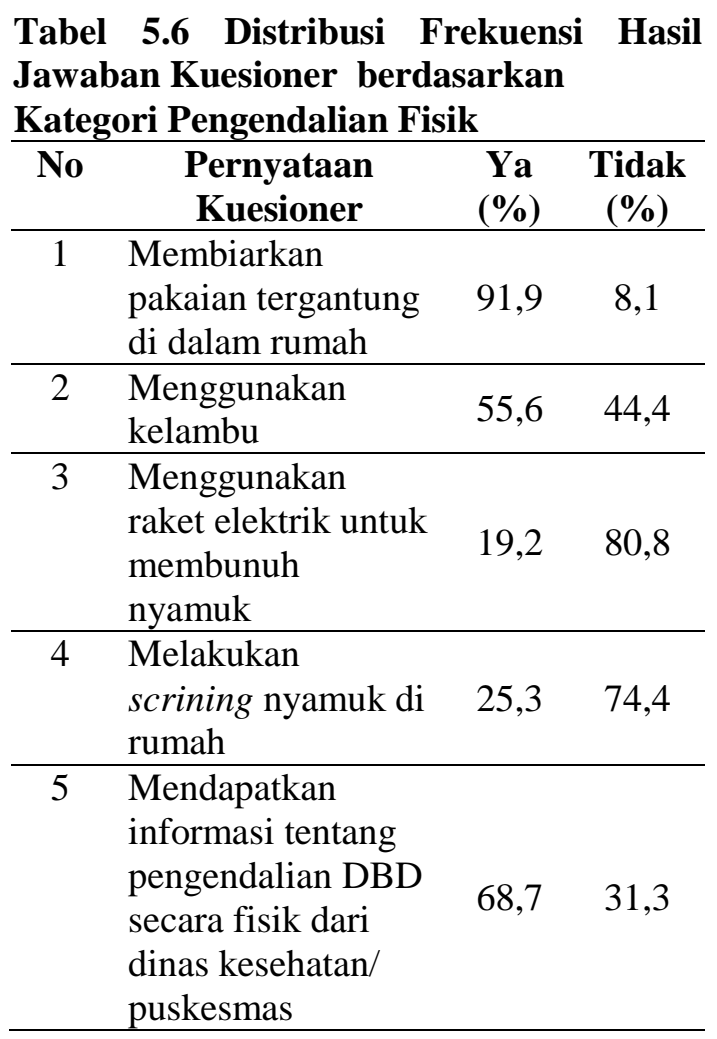

Berdasarkan hasil distribusi frekuensi
jawaban responden pada variabel
pengendalian fisik, diketahui bahwa hampir
seluruh responden yaitu $91,9 \%$ menyatakan
bahwa mereka memiliki kebiasaan
menggantung pakaian di dalam rumah.
Hampir seluruh responden yaitu 80,8 \%
tidak menggunakan alat perlindungan diri


seperti raket elektrik untuk membunuh nyamuk, dan lebih dari separuk responden yaitu 74,4\% mengaku bahwa mereka tidak melakukan pencarian nyamuk di rumah terutama di kamar tidur untuk menghindari gigitan nyamuk.

Menurut analisa peneliti, hal ini dapat terjadi karena kurangnya pengawasan dari petugas kesehatan yang datang memeriksa jentik dirumah atau di lingkungan mereka, begitu juga dengan himbauan terkait program pengendalian vektor DBD yang disampaikan kepada masyarakat, masih ada responden menyatakan bahwa tidak ada himbauan yang disampaikan oleh petugas baik mengenai kasus maupun terkait program pengendalian yang harus mereka lakukan. Seharusnya para pelaksana program mempunyai sikap positif dan memberikan dukungan penuh terhadap implementasi kebijakan program, sehingga terdapat kemungkinan yang besar implementasi kebijakan akan terlaksana sesuai dengan harapan. Oleh sebab itu, perlu adanya pelatihan yang diberikan kepada para pelaksana, agar mereka tahu dan memahami apa yang menjadi kewajiban mereka. Selain itu diperlukan juga evaluasi terhadap para pelaksana dalam meningkatkan partisipasi masyarakat pada program penanggulangan DBD.

\section{Pengendalian Kimiawi}

Variabel pengendalian kimiawi dikelompokkan menjadi dua kategori yaitu buruk dan baik. Gambaran distribusi responden berdasarkan upaya pengendalian kimiawi dapat dilihat pada tabel 5.7.

\begin{tabular}{ccc}
$\begin{array}{l}\text { Tabel 5.7 } \\
\text { Berdasarkan } \\
\text { Kimiawi dalam } \\
\text { Vektor DBD }\end{array}$ & $\begin{array}{c}\text { Distribusi } \\
\text { Kategori }\end{array}$ & $\begin{array}{c}\text { Pesponden } \\
\text { Pengendalian } \\
\text { Pengendalian }\end{array}$ \\
$\begin{array}{c}\text { Pengendalian } \\
\text { Kimiawi }\end{array}$ & $\mathbf{f}$ & $\%$ \\
\hline Buruk & 78 & 78,8 \\
Baik & 21 & 21,2 \\
Total & 99 & 100,0 \\
\hline
\end{tabular}

Tabel 5.7 menunjukkan bahwa dari 99 responden, terdapat $78,8 \%$ responden yang tergolong dalam kategori buruk dalam melakukan pengendalian kimiawi.

Menurut Kemenkes RI (2013), pengendalian vektor secara kimiawi dapat ditempuh dengan dua teknik untuk pengendalian secara kimiawi, yaitu pengasapan (fogging) dengan menggunakan senyawa kimia malathion dan fenthion, yang berguna untuk mengurangi penularan sampai batas waktu tertentu, dan pemberantasan larva nyamuk dengan zat kimia (abate).

Berikut dapat dilihat tabel distribusi frekuensi hasil jawaban kuesioner untuk variabel pengendalian kimiawi.

\section{Tabel 5.8 Distribusi Frekuensi Jawaban Responden Berdasarkan Pengendalian Kimiawi}

\begin{tabular}{|c|c|c|c|}
\hline No. & Kuesioner & $\begin{array}{c}\text { Ya } \\
(\%)\end{array}$ & $\begin{array}{c}\text { Tidak } \\
(\%)\end{array}$ \\
\hline 1. & $\begin{array}{l}\text { Mencari tahu kepada } \\
\text { petugas tentang } \\
\text { kegunaan pemberian } \\
\text { Abate }\end{array}$ & 7,1 & 92,9 \\
\hline 2. & $\begin{array}{l}\text { Meletakkan bubuk } \\
\text { Abate pada bak atau } \\
\text { wadah penampungan } \\
\text { air }\end{array}$ & 2,0 & 98,0 \\
\hline 3. & $\begin{array}{l}\text { Meminta Abate kepada } \\
\text { petugas kesehatan jika } \\
\text { persediaan habis }\end{array}$ & 0 & 100,0 \\
\hline 4. & $\begin{array}{l}\text { Menggunakan obat } \\
\text { anti nyamuk bakar } \\
\text { untuk menghindari } \\
\text { gigitan nyamuk }\end{array}$ & 9,1 & 90,9 \\
\hline 5. & $\begin{array}{l}\text { Menggunakan obat } \\
\text { anti nyamuk semprot } \\
\text { untuk menghindari } \\
\text { gigitan nyamuk }\end{array}$ & 2,0 & 98,0 \\
\hline 6. & $\begin{array}{l}\text { Menggunakan obat } \\
\text { anti nyamuk oles, } \\
\text { untuk menghindari } \\
\text { gigitan nyamuk }\end{array}$ & 2,0 & 98,0 \\
\hline 7. & $\begin{array}{l}\text { Melakukan } \\
\text { penyemprotan di luar } \\
\text { rumah anda seperti di } \\
\text { kandang ternak dan } \\
\text { teras }\end{array}$ & 1,0 & 99,0 \\
\hline 8. & $\begin{array}{l}\text { Memberi izin petugas } \\
\text { dalam pelaksanaan } \\
\text { fogging (pengasapan) }\end{array}$ & 98,0 & 2,0 \\
\hline 9. & $\begin{array}{l}\text { Mencari informasi } \\
\text { tentang kegunaan } \\
\text { fogging kepada } \\
\text { petugas }\end{array}$ & 6,1 & 93,9 \\
\hline
\end{tabular}




\begin{tabular}{llll}
\hline 10. & $\begin{array}{l}\text { Membuka pintu dan } \\
\text { jendela rumah ketika } \\
\text { dilakukan fogging } \\
\text { (pengasapan) }\end{array}$ & 11,1 & 88,9 \\
\hline 11. & $\begin{array}{l}\text { Menjadi kader fogging } \\
\text { di lingkungan }\end{array}$ & 9,1 & 90.9 \\
\hline 12. & $\begin{array}{l}\text { Mendapatkan } \\
\text { informasi tentang } \\
\text { pengendalian DBD } \\
\text { secara kimiawi dari } \\
\text { dinas } \\
\text { kesehatan/puskesmas }\end{array}$ & 66,7 & 33,3 \\
\hline
\end{tabular}

Berdasarkan tabel 5.8 distribusi frekuensi jawaban responden dari kuesioner pengendalian kimiawi, ditemukan sebanyak $100 \%$ responden tidak meminta bubuk Abate kepada petugas kesehatan jika persediaan habis, sebanyak $99 \%$ responden tidak melakukan penyemprotan di luar rumah seperti di kandang ternak dan teras, dan sebanyak $98 \%$ responden tidak meletakkan bubuk abate pada bak penampungan air.

Masyarakat di wilayah kerja Puskesmas Air Dingin sangat jarang menggunakan obat anti nyamuk. Sebanyak $9,1 \%$ masyarakat menggunakan obat nyamuk bakar, dan hanya $2 \%$ yang menggunakan obat nyamuk semprot dan oles. Adapun bentuk partisipasi masyarakat dalam upaya pengendalian kimiawi yaitu mengizinkan petugas kesehatan melakukan fogging (pengasapan).

Rendahnya partisipasi masyarakat terjadi karena kurangnya kesadaran masyarakat untuk melakukan upaya pengendalian kimiawi seperti menggunakan bubuk abate pada bak penampungan air dan menggunakan obat anti nyamuk. Selain itu, rendahnya peran petugas kesehatan dalam mensosialisasikan penaburan bubuk abate karena masyarakat mengaku bahwa petugas kesehatan tidak pernah membagikan bubuk abate.

Upaya pengendalian kimiawi dilakukan untuk memberantas nyamuk dewasa maupun dalam bentuk larva dan pupa. Untuk nyamuk dewasa dilakukan dengan cara pengasapan (thermal fogging) atau pengabutan (cold fogging) dengan berbagai jenis insektisida misalnya golongan organophospat atau pyrethroid synthetic. Untuk pemberantasan larva nyamuk dapat menggunakan abate $1 \%$ SG. Cara ini biasanya digunakan dengan menaburkan bubuk abate ke dalam bejana tempat penampungan air seperti bak mandi, tempayan, drum dapat mencegah adanya jentik selama 2-3 bulan (Tairas, 2015).

Seharusnya petugas kesehatan membagikan dan menjelaskan cara penggunaan bubuk abate kepada masyarakat wilayah kerja Puskesmas Air Dingin yang merupakan daerah endemis DBD di Kota Padang. Selain itu juga memberikan informasi terkait penggunaan obat anti nyamuk yang sesuai dengan petunjuk penggunaan agar tidak menimbulkan bahaya keracunan pada manusia ataupun resistensi pada nyamuk.

\section{Pengendalian Biologi}

Variabel pengendalian secara biologi dikelompokkan menjadi dua kategori yaitu buruk dan baik. Gambaran distribusi responden berdasarkan upaya pengendalian secara biologi dapat dilihat pada tabel 5.9.

\begin{tabular}{ccc}
$\begin{array}{l}\text { Tabel } \\
\text { Berdasarkan } \\
\text { Biologi dalam } \\
\text { Vektor DBD }\end{array}$ & $\begin{array}{c}\text { Distribusi } \\
\text { Kategori } \\
\text { Program }\end{array}$ & $\begin{array}{c}\text { Responden } \\
\text { Pengendalian } \\
\text { Pengendalian }\end{array}$ \\
\hline $\begin{array}{c}\text { Pengendalian } \\
\text { Biologis }\end{array}$ & f & \% \\
\hline Buruk & 35 & 35,4 \\
Baik & 64 & 64,6 \\
Total & 99 & 100,0 \\
\hline
\end{tabular}

Tabel 5.9 menunjukkan bahwa dari 99 responden, terdapat $35,4 \%$ responden yang tergolong dalam kategori buruk dalam melakukan pengendalian biologi.

Berikut dapat dilihat pada tabel 5.10 distribusi frekuensi hasil jawaban kuesioner untuk variabel pengendalian biologi.

Tabel 5.10 Distribusi Frekuensi Jawaban Responden Berdasarkan Kuesioner Pengendalian Biologi

\begin{tabular}{llcc}
\hline No. & \multicolumn{1}{c}{ Kuesioner } & $\begin{array}{c}\text { Ya } \\
(\boldsymbol{\%})\end{array}$ & $\begin{array}{c}\text { Tidak } \\
(\mathbf{\%})\end{array}$ \\
\hline 1. & $\begin{array}{l}\text { Memiliki tempat }- \\
\text { tempat } \\
\text { perkembanganbiakan }\end{array}$ & 12,1 & 87,9 \\
& & \\
\hline
\end{tabular}




\begin{tabular}{|c|c|c|c|}
\hline & $\begin{array}{l}\text { nyamuk seperti } \\
\text { kolam dan rawa - } \\
\text { rawa }\end{array}$ & & \\
\hline 2. & $\begin{array}{l}\text { Jika 'ya', } \\
\text { memelihara ikan }\end{array}$ & 12,1 & 87,9 \\
\hline 3. & $\begin{array}{l}\text { Menanam tanaman } \\
\text { repellent (tanaman } \\
\text { pengusir nyamuk } \\
\text { seperti : serai wangi, } \\
\text { kincung, lavender. } \\
\text { kemangi, ruku-ruku) }\end{array}$ & 91,9 & 8,1 \\
\hline 4. & $\begin{array}{l}\text { Mendapatkan } \\
\text { informasi tentang } \\
\text { pengendalian DBD } \\
\text { secara biologi dari } \\
\text { dinas } \\
\text { kesehatan/puskesmas }\end{array}$ & 69,7 & 30,3 \\
\hline
\end{tabular}

Berdasarkan tabel 5.10 distribusi frekuensi jawaban responden dari kuesioner pengendalian biologi, ditemukan sebanyak 30,3\% tidak mendapatkan informasi tentang pengendalian DBD secara biologi dari dinak kesehatan/puskesmas.

Partisipasi masyarakat dalam upaya pengendalian biologi sudah cukup baik. Sebanyak 91,9 \% responden menanam tanaman pengusir nyamuk seperti serai wangi, kincung dan ruku-ruku di pekarangan rumahnya. Masyarakat sudah banyak mendapatkan informasi dari dinas kesehatan/puskesmas terkait dengan pengendalian biologis $(69,7 \%)$.

Anggraeni (2010) menyatakan pengendalian larva Aedes aegypti secara biologi atau hayati menggunakan organisme yang dalam pengendalian secara hayati umumnya bersifat predator, parasitik atau patogenik. Beberapa agen hayati yang digunakan untuk memberantas nyamuk Aedes aegypti seperti ikan kepala timah (Aplocheilus panchax), ikan nila (Oreochronis nilocitus), ikan guppy (Poecilia reticulata), ikan mujair (Oreochronis mossambicus), ikan cupang (Betta splendens), yang mangsanya adalah larva nyamuk. Selain itu, tanaman yang menimbulkan bau yang tidak disukai oleh nyamuk Aedes aegypti seperti akar wangi (vertiver zizanoides). Ekstrak akar wanginya dapat membunuh larva nyamuk Aedes aegypti dalam waktu kurang lebih dari 2 jam
(Soedarto, 2012). Masyarakat diharapkan dapat menanam tanaman pengusir nyamuk di halaman rumah untuk menghindari berkembangbiaknya nyamuk vektor di sekitar rumah.

\section{Keberadaan Jentik}

Variabel keberadaan jentik dikelompokkan menjadi dua kategori yaitu positif dan negatif. Gambaran distribusi responden berdasarkan keberadaan jentik dapat dilihat pada tabel 5.11.

\begin{tabular}{lcc}
$\begin{array}{l}\text { Tabel 5.11 Distribusi Rumah Responden } \\
\text { berdasarkan Kategori Keberadaan Jentik } \\
\text { Vektor DBD }\end{array}$ \\
$\begin{array}{c}\text { Keberadaan } \\
\text { Jentik }\end{array}$ & Frekuensi & $\%$ \\
\hline Positif & 52 & 52,5 \\
Negatif & 47 & 47,5 \\
Total & 99 & 100,0 \\
\hline
\end{tabular}

Tabel 5.11 menunjukkan bahwa keberadaan jentik positif di rumah responden sebesar $52,5 \%$ dan negatif sebesar $47,5 \%$.

Berdasarkan hasil penelitian terdapat sebanyak 840 tempat penampungan air (TPA) yang potensial untuk perkembangbiakan vektor DBD yaitu jentik nyamuk Aedes spp di 99 rumah responden. Berdasarkan jumlah tersebut TPA yang positif jentik (larva/pupa) nyamuk sebanyak 81 buah yang terdiri atas 26 buah $(32,1 \%)$ TPA bersih, 51 buah $(62,9 \%)$ TPA bekas, 1 $(1,2 \%)$ saluran air, dan $3(3,7 \%)$ TPA alamiah. TPA yang paling banyak positif jentik adalah bak mandi sebanyak 18 buah $(22,3 \%)$, ban bekas sebanyak 17 buah (21 $\%)$, dan ember bekas sebanyak 17 buah (21 $\%)$.

Bak mandi merupakan TPA yang paling banyak ditemukan jentik karena masyarakat jarang menguras bak mandi yang seharusnya dibersihkan minimal satu kali dalam satu minggu. Barang-barang bekas seperti ban bekas dan ember bekas masih banyak ditemukan berserakan di sekitar rumah masyarakat yang dapat menjadi tempat potensial untuk perkembangbiakan nyamuk vektor DBD yang sering diabaikan oleh masyarakat. 
Masyarakat tidak dapat mengubur barang bekas karena mereka beranggapan barang bekas masih dapat dijual sehingga ditumpuk di halaman rumah. Selain itu, tidak tersedianya lahan untuk mengubur barang bekas tersebut.

Hasil penelitian ini sejalan dengan penelitian Faridah (2017) di Kota Bandung bahwa bak mandi merupakan TPA yang paling banyak ditemukan larva nyamuk. Bak mandi merupakan TPA yang digunakan untuk keperluan sehari-hari sehingga umumnya memiliki volume yang cukup besar, dapat menyimpan cadangan air dalam waktu lama sehinga sangat potensial untuk menjadi tempat perkembangbiakan nyamuk.

Menurut Soegijanto (2006), tempat berkembangbiak Aedes aegypti yang utama di dalam rumah adalah bak mandi, bak wc, tandon air minum, tempayan, gentong tanah liat, gentong plastik, ember, drum dan vas tanaman hias.

Berdasarkan hasil survei jentik nyamuk yang telah dilakukan dapat diketahui angka kepadatan jentik yang disajikan dalam tabel 5.12.

Tabel 5.12 Kepadatan populasi larva nyamuk (ABJ, HI, CI, BI) di Wilayah Kerja Puskesmas Air Dingin Kota Padang

Indeks Kepadatan Vektor

\begin{tabular}{ll}
\hline ABJ (Angka Bebas Jentik) & $47,5 \%$ \\
HI (House Index) & 52,5 \\
CI (Container Index) & 9,6 \\
BI (Breteau Index) & 81,8 \\
\hline
\end{tabular}

Tabel 5.13 WHO density figure

\begin{tabular}{cccc}
\hline $\begin{array}{c}\text { Density } \\
\text { figure }\end{array}$ & $\begin{array}{c}\text { House } \\
\text { Index }\end{array}$ & $\begin{array}{c}\text { Container } \\
\text { Index }\end{array}$ & $\begin{array}{c}\text { Breteau } \\
\text { Index }\end{array}$ \\
& $(\mathrm{HI})$ & $(\mathrm{CI})$ & $(\mathrm{BI})$ \\
\hline
\end{tabular}

\begin{tabular}{cccc}
\hline 1 & $1-3$ & $1-2$ & $1-4$ \\
2 & $4-7$ & $3-5$ & $5-9$ \\
3 & $8-17$ & $\mathbf{6 - 9}$ & $10-19$ \\
4 & $18-28$ & $10-14$ & $20-34$ \\
5 & $29-37$ & $15-20$ & $35-49$ \\
6 & $38-49$ & $21-27$ & $50-74$ \\
7 & $\mathbf{5 0 - 5 9}$ & $28-31$ & $\mathbf{7 5 - 9 9}$ \\
8 & $60-76$ & $32-40$ & $100-199$ \\
9 & $>77$ & $>41$ & $>200$
\end{tabular}

Sumber : WHO, 2009

Angka bebas jentik di Wilayah Kerja Puskesmas Air Dingin sebesar 47,5 \% masih jauh jika dibandingkan dengan target nasional yaitu $95 \%$ (Kemenkes, 2010) Angka house index (HI) di Wilayah Kerja Puskesmas Air Dingin cukup tinggi yaitu 52,5. Jika angka HI dihubungkan dengan angka kepadatan vektor dari WHO (density figure) (WHO, 2009) pada Tabel 5.13, maka wilayah tersebut berada pada skala 7 yang berarti memiliki risiko penularan tinggi terhadap penyakit DBD. Angka container index (CI) di Wilayah Kerja Puskesmas Air Dingin yaitu 9,6. Angka CI berada pada skala 3 yang berarti wilayah tersebut memiliki risiko penularan sedang. Angka breteau index (BI) di Wilayah Kerja Puskesmas Air Dingin cukup tinggi yaitu 81,8. Angka BI di wilayah tersebut berada pada skala 7 yang berarti memiliki risiko penularan tinggi terhadap penyakit DBD.

Angka indeks kepadatan vektor yang tinggi disebabkan karena masih kurangnya partisipasi masyarakat dalam melaksanakan pengendalian vektor DBD dengan melakukan modifikasi lingkungan, manipulasi lingkungan, pengendalian secara fisik, pengendalian kimiawi, dan pengendalian secara biologis.

\section{KESIMPULAN DAN SARAN Kesimpulan}

Hasil penelitian menunjukkan bahwa sebesar 52,5 \% rumah responden positif jentik, sebesar $32,3 \%$ responden tergolong dalam kategori buruk dalam melakukan modifikasi lingkungan, sebesar $58,6 \%$ responden tergolong dalam kategori buruk dalam melakukan manipulasi lingkungan, sebesar $30,3 \%$ responden 
tergolong dalam kategori buruk melakukan pengendalian fisik, sebesar 78,8 \% responden tergolong dalam kategori buruk melakukan pengendalian kimiawi, dan sebesar 35,4\% responden tergolong dalam kategori buruk melakukan pengendalian biologi dalam program pengendalian vektor DBD.

\section{Ucapan Terima Kasih}

Ucapan terima kasih kepada Dinas Kesehatan Kota Padang serta Kepala Puskesmas Air Dingin yang membantu dalam proses penelitian. Kepada rekan-rekan di Fakultas Kesehatan Masyarakat Universitas Baiturrahmah yang telah memberikan dukungannya.

\section{DAFTAR PUSTAKA}

Anggraeni. 2010. Stop Demam Berdarah Dengue. Bogor : Cita Insan Madani.

Dinas Kesehatan Sumatera Barat. 2016. Profil Kesehatan Sumbar 2016. Padang : Dinkes Sumbar.

Dinas Kesehatan Kota Padang. 2016. Profil Kesehatan Kota Padang 2016. Padang : Dinkes Kota Padang.

Faridah, L., Respati, T., Sudigdoadi, S., dan Sukandar, H. 2017. Gambaran Partisipasi Masyarakat terhadap Pengendalian Vektor Melalui Kajian Tempat Perkembangbiakan Aedes aegypti di Kota Bandung. MKB. Volume 49 No 1, Maret 2017.

Jingga, AL. 2011. Upaya Pengendalian DBD [On Line]. Diakses dari: http://jinggadelia.community.undip. ac.id/2011/03/11/upaya-

pengendalian-DBD $\quad[8$ Agustus 2018].

Kemenkes. 2010. Buletin Jendela Epidemiologi. Volume 2, Agustus, 2010.

Kementerian Kesehatan RI. 2013. Pedoman Pengendalian Demam Berdarah Dengue di Indonesia. Jakarta : Direktorat Jenderal Pengendalian Penyakit dan Penyehatan Lingkungan
Kementerian Kesehatan RI. 2016. Profil Kesehatan Indonesia 2016. Jakarta: Kemenkes RI.

Kusnoputranto, Haryoto. 2000. Kesehatan Lingkungan. Jakarta: Fakultas Kesehatan Masyarakat Universitas Indonesia.

Prasetyowati, H., Santya, R.N.R.E. and Nurindra, R.W., 2015. Motivasi dan Peran Serta Masyarakat Dalam Pengendalian Populasi Aedes Spp Di Kota Sukabumi. Jurnal Ekologi Kesehatan, 14(2 Jun), pp.106-115.

Soedarto. 2012. Demam Berdarah Dengue. Jakarta: Sagung Seto.

Soegijanto S. 2006. Demam Berdarah Dengue. Surabaya: Airlangga Universitt Press.

Tairas, S., Kandou, G.D dan Posangi, J. 2015. Analisis Pelaksanaan Pengendalian Demam Berdarah Dengue di Kabupaten Minahasa Utara. JIKMU, 5(1) Januari 2015.

WHO. 2009. Dengue : Guidelines for Diagnosis, Treatment, Prevention, and Control. France: WHO Press. 